Fallos contradictorios en la Corte Suprema de Justicia

\section{¿Son procesos de conocimiento los juicios posesorios?}

\author{
La Primera y Segunda Salas de lo Civil y Mercantil dan por obvio que \\ los procesos posesorios (amparo posesorio y obra nueva) son procesos \\ de conocimiento. En cambio, la Tercera Sala de lo Civil y Mercantil, \\ expresamente declara que no lo son.
}

La Constitución Política de la República del Ecuador, en el artículo 197 dispone que, "la Corte Suprema de Justicia en pleno, expedirá la norma dirimente que tendrá carácter obligatorio, mientras la ley no determine lo contrario, en caso de fallos contradictorios sobre un mismo punto de derecho, dictados por las Salas de Casación, los Tribunales Distritales o las Cortes Superiores". Son conformes a este mandato el artículo 14 de la Ley Orgánica de la Función Judicial y el artículo 19 de la Ley de Casación.

A fin de que la Corte Suprema de Justicia en pleno pueda cumplir con el mandato constitucional, los presidentes de la diferentes salas de la Corte remitirán al Presidente de la Corte Suprema el informe relativo a fallos contradictorios. Es así que el Presidente de la Primera Sala de lo Civil y Mercantil dirigió al Presidente de la Corte Suprema un oficio en el que informó que, a criterio de esa Sala, hay contradicción entre lo que ésta mantiene en cuanto "considera que las acciones de amparo posesorio y de obra nueva, dan origen a procesos de conocimiento, por lo que en ellos cabe recurso de casación de la resolución de segundo nivel (siempre que se cumplan los demás requisitos de ley)"; y lo que sostienen los Magistrados de la Tercera Sala de lo Civil y Mercantil, que consideran que las acciones de amparo posesorio y de obra nueva no son procesos de conocimiento y, por tanto, no cabe la interposición de recurso de casación.

Antes de entrar a nuestro análisis recordemos que, cuando se expidieron las reformas a la Ley de Casación, el 08 de abril de 1997, se introdujeron, en el artículo 2 criterios importantes para establecer la procedibilidad de sentencias y autos al recurso. Estos criterios son: a) que pongan fin a los procesos; b) que sean dictados dentro de procesos de conocimiento, y c) y proferidos por las Cortes Superiores, por los Tribunales Distritales de lo Fiscal y de lo Contencioso Administrativo.

La contradicción radica en que la Primera y Segunda Salas de lo Civil y Mercantil dan por obvio que los interdictos o procesos posesorios (amparo posesorio y obra nueva) son procesos de conocimiento, ya que, en los fa- llos sobre dicha materia no se discute sobre su naturaleza y, más bien, se entra a conocer sobre el fondo del recurso, siendo, entonces, su silencio una tácita afirmación de la naturaleza cognitiva de esos procesos. En cambio, la Tercera Sala de lo Civil y Mercantil, expresamente declara que no son procesos de conocimiento.

Así, dice la Tercera Sala en su fallo:

"QUINTO.- En cuanto a que los juicios posesionarios no son de conocimiento, tanto la doctrina como la jurisprudencia están acordes en sostener que dichos juicios no tienen ese carácter, ya que se originan en los interdictos romanos establecidos para regular de urgencia determinado estado posesorio, y sus decisiones, como queda dicho, no son inmutables. Así tenemos, que el maestro Víctor Manuel Peñaherrera en su obra La Posesión, Págs. 169 y siguientes' sostiene que : 'Mediante juicios posesorio, el poseedor recobra o afianza su posesión ; pero no de modo definitivo... El triunfo en este juicio no impide de manera alguna el que enseguida pueda disputarse el derecho en juicio petitorio, y declararse que esa posesión amparada y protegida en el posesorio, ha sido injusta e ilegal', y continúa el tratadista indicando que 'el fallo expedido en juicio posesorio no produce excepción de cosa juzgada en el petitorio', así como que 'pendiente el juicio posesorio promovido por el poseedor despojado o perturbado, puede su contrincante suscitarle el juicio ordinario de propiedad', a más de que 'el mismo actor en el juicio posesorio, si prevé el mal éxito de su acción o tiene algún otro motivo puede suscitar el juicio petitorio, sin que haya derecho a oponerle la excepción de litis pendencia" .

Para nuestro análisis es conveniente hacer las siguientes consideraciones :

\section{Clasificación de los Procesos.-}

A pesar de concebirse el proceso como una unidad fundamental, los autores establecen una tipología procesal, cada uno, desde diferentes criterios. Así, por ejemplo, el autor español Jaime Guasp establece la siguiente: de acuerdo al sector del ordenamiento jurídico al que pertenece la materia de que el proceso se ocupa, distingue el proceso civil, el proceso penal, el proceso admi- 
nistrativo, el proceso internacional y el proceso canónico. De acuerdo a las clases de pretensiones procesales, distingue el proceso de cognición (constitutivos, declarativos y de condena) y el de ejecución. Desde el punto de vista de las funciones del proceso, el autor italiano Francisco Carnelutti los divide, según se dirija a la reglamentación de un conflicto de intereses en acto o en potencia, se distingue el proceso contencioso del proceso voluntario. Según que la reglamentación ocurra en el campo de la formación o en el de la actuación del derecho, se distingue el proceso cognitivo del proceso ejecutivo. Según que la regulación opere inmediata o mediatamente se distingue el proceso definitivo del proceso cautelar. Según que regule un conflicto singular de intereses o una categoría de conflictos, se distingue entre proceso singular y proceso colectivo o universal. Por su parte, el autor uruguayo Enrique Véscovi, además de las clasificaciones ya citadas, distingue el proceso, según su estructura, en proceso simple y monitorio. Por la forma del procedimiento, en proceso verbal y escrito . En el Anteproyecto del Código de Procesamiento Civil Tipo Iberoamericano, se distinguen las siguientes categorías : procesos preliminares, procesos cautelares, procesos incidentales, procesos de conocimiento, procesos de ejecución, procesos voluntarios, procesos concursales, procesos arbitrales y procesos regidos por normas internacionales.

Para efectos de nuestro estudio nos interesa aquella tipología que se establece en correspondencia con las tres manifestaciones de la Jurisdicción y que, a la vez, es conforme a la definición teleológica que del proceso civil trae el autor alemán Leo Rosenberg: es "el procedimiento jurídicamente regulado para la protección del ordenamiento jurídico mediante declaración, realización y aseguramiento (principalmente) de los derechos y relaciones jurídicas de derecho civil"

En efecto, la función jurisdiccional comprende tres manifestaciones : (1) la actividad por medio de la cual el Estado aplica la norma general y abstracta al caso concreto e individualiza el mandato legal - esta función se relaciona con la significación etimológica de jurisdicción (decir el derecho). (2) La actividad que se lleva a cabo para que ese mandato concreto sea prácticamente observado, llamada función de coacción porque ejecuta lo juzgado. (3) Finalmente la actividad por medio de la cual asegura que el resultado del proceso se cumpla y no llegue demasiado tarde.

A cada una de estas funciones corresponde un tipo de proceso.

\subsection{Proceso de conocimiento.-}

Proceso de conocimiento es aquel que tiene por finalidad la declaración de un derecho o responsabilidad o de la constitución de una relación jurídica . Enrique Véscovi dice que es aquel que tiene por finalidad "producir una declaración de certeza sobre una situación jurídica", por ello añade que en esta clase de procesos el juez "juzga" porque, según expresión conocida "dice el derecho" . Eduardo Couture, sobre las acciones de conocimiento, dice que son aquellas "en que se procura tan solo la declaración o determinación del derecho".

Según el procesalista español Jaime Guasp, estos procesos se llaman de conocimiento ya que en ellos "existe y no puede faltar el conocimiento por el juez del fondo del asunto, conocimiento que, según su denominación técnica de cognitio judicial da nombre a toda la figura"

Sin embargo, como bien lo enseña el tratadista español, el proceso de cognición es una subdivisión de la del proceso en general, es una clase en la que caben distintas individualidades, según la función del juez y el tipo de pretensión u objeto litigioso.

Así, el proceso de conocimiento se clasifica en: a) proceso de condena o prestación, b) proceso declarativo puro o de mero acertamiento y c) proceso constitutivo o de acierto constitutivo.

\subsubsection{Proceso de condena.-}

En estos procesos el juez declara la existencia o inexistencia de un derecho del actor y a la vez declara una responsabilidad del demandado, en virtud de la cual queda obligado. Por ello, el autor italiano Carnelutti, dice que este proceso concluye con un juicio sobre la pretensión, pero además con un mandato sobre aquello que es necesario hacer para restablecer la lesión, y que va dirigido al demandado

Hernando Devis Echandía, citando a Ugo Rocco, señala que en estos procesos "la condena del demandado va ligada, por lo tanto, a la declaración de que el derecho del demandante existe como base de aquella" .

\subsubsection{Proceso declarativo.-}

En este proceso, el juez únicamente declara un derecho o una relación jurídica. Aunque, como indica Carnelutti, también pueden ser objeto de acertamiento hechos de los que derivan determinados efectos jurídicos, es decir la eficacia jurídica del hecho y no su modo material de ser.

\subsubsection{Proceso constitutivo.-}

Este proceso tiene como objeto la creación, modificación o extinción de una relación jurídica.

La diferencia de estos procesos con los declarativos está, como lo enseña Carnelutti, en que la declaración en los procesos constitutivos modifica de algún modo la relación jurídica. En cambio, en los proceso declarativos, la declaración del juez no agrega nada a lo que ya existe por efecto de la norma. Estos procesos se diferencian, además, de los procesos de condena y de los declarativos, en que no tienen eficacia en el mundo jurídico material, en cambio los procesos constitutivos sí la tienen. Por ello Guasp dice que: "un proceso es constitutivo cuando la sentencia que en él se dicta, caso de que sea estimatoria, lleva consigo la creación, modificación o extinción de alguna situación jurídica ... Ni los procesos declarativos ni los de condena producen esta eficacia, los declarativos porque se limitan a constatar o hacer patente la situación material que antes existía ... y dentro de los procesos de ejecución sus resultados tampoco innovan en las situaciones jurídicas por regla general".

\section{2. Proceso de Ejecución.-}

La segunda función de la jurisdicción se cumple a través del proceso de ejecución. Éste se desarrolla cuando los derechos controvertidos entre las partes han sido comprobados por sentencia y, por ende, le corresponde su realización o ejecución. Por ello dice Carnelutti que en estos procesos ya no estamos ante una pretensión discutida que requiere de declaración por parte del juez, sino de lo que Carnelutti llama pretensión insatisfecha, donde no es necesaria la declaración sino la ejecución 
del mandato o ejecución .

Según el autor italiano la principal diferencia entre el proceso jurisdiccional - como lo llama al proceso de conocimiento- y el proceso ejecutivo está en que la razón es el instrumento del primero y la fuerza del segundo, de ahí que el proceso ejecutivo está subordinado al proceso jurisdiccional, pues hasta que no se haya establecido la razón, no debe ser usada la fuerza: 'si la razón no sirve por sí sola, habrá que usa la fuerza" .

En estos procesos la fase de conocimiento del juez es más limitada, ya que el juez no se encuentra ante dos partes que se disputan la razón y, por lo tanto, no debe buscar cuál de las dos tenga la razón en verdad, sino ante una parte que quiere tener una cosa, tiene el derecho para ello y otra que no quiera darla. Su función se limita a procurar al titular del derecho sin o contra la voluntad del obligado, la satisfacción del mismo interés que le habría ocasionado el cumplimiento .

\section{3. Proceso cautelar.-}

Algunos autores se refieren a él como un proceso subordinado o intermedio (Véscovi - Calamandrei), sin embargo la doctrina contemporánea se inclina por considerarlo como un proceso autónomo.

Para comprender este tipo de procesos, se debe tener en cuenta que la declaración de una certeza (sobre derechos o sobre una relación jurídica) que se obtiene en el proceso de conocimiento con frecuencia requiere de bastante tiempo. Para que, al dictarse una resolución, ésta no llegue tarde o por su retardo sea inaplicable, se opera un proceso cautelar justamente para impedir la amenaza de inminentes riesgos y evitar lesiones.

\section{Sobre la NATURAleza de la posesión Y DE LOS PROCESOS POSESORIOS.-}

\section{1. Naturaleza jurídica de la posesión.-}

Una vez que hemos analizado a grandes rasgos la clasificación de los procesos, debemos ubicar a cuál de estas categorías pertenecen los procesos posesorios. Mas, para hacerlo hay que entender primero la naturaleza jurídica de la posesión, que desde siempre ha sido objeto de controversia. Sólo así se podrá comprender la naturaleza de las acciones posesorias.

El artículo 734 del Código Civil define la posesión de la siguiente manera : "Posesión es la tenencia de una cosa determinada con ánimo de señor o dueño ; sea que el dueño o el que se da por tal tenga la cosa por sí mismo, o bien por otra persona en su lugar y a su nombre". Según esta definición legal, componen la posesión dos elementos : la tenencia material de la cosa y el ánimo de señor y dueño.

A criterio de Juan Larrea Holguín, "se trata de una definición suficientemente precisa, pero al mismo tiempo con el grado de generalidad y abstracción bastantes como para permitir su conveniente adaptación a las nuevas corrientes doctrinales, surgidas con posterioridad a la redacción del Código", pues ubica a la posesión como algo intermedio entre la mera tenencia y la propiedad: no es ni lo uno ni lo otro.

La problemática de si la posesión es un mero hecho o un derecho ha estado vigente desde siempre, y se distingue claramente en esta discusión dos posiciones. Por eso partiremos el análisis preguntándonos si la posesión es una relación jurídica o nọ lo es.

Una primera tendencia mira hacia el Derecho Romano, que considera que relación jurídica equivale a vínculo de derecho (jus vinculum), pero restringida al derecho personal entre dos personas. Autores como Carnelutti mantienen este criterio y, por ello, ven en la posesión un mero hecho que, aunque generador de derechos, no tiene carácter de relación jurídica .

El derecho moderno ha extendido considerablemente el concepto. Uno de los exponentes de esta corriente es Savigny, quien define la relación jurídica como "el dominio de la voluntad libre" y añade : "ese dominio se revela en un obrar de la voluntad, ya sobre la propia persona ya sobre el mundo exterior. El mundo exterior se integra por otros sujetos de derecho y por las cosas de la naturaleza". Es decir que en este concepto de relación jurídica se integran, no sólo las relaciones entre personas sino entre personas y cosas

El autor alemán Leo Rosenberg comparte este criterio: "cuando hablamos de relación jurídica, nos referimos a una relación concreta, regulada en forma jurídica. Según los hechos expuestos, entre personas o de una persona con un objeto o sobre consecuencias jurídicas particulares de tal relación" . Al amparo de esta teoría la posesión es una relación jurídica regulada por la ley.

Finalmente: las más modernas doctrinas del derecho civil amplían aún más la expresión relación jurídica, en cuanto consideran que cualquier relación de la vida de las personas a la cual las normas jurídicas atribuyan efectos o consecuencias jurídicas, es tal relación. El autor colombiano Arturo Valencia Zea, estudioso del tema de la posesión, comparte este criterio, pues permite hacer servir la expresión a fenómenos jurídicos que no alcanzan a constituir derechos subjetivos.

Para el autor colombiano si otros autores restringen el concepto de relación jurídica al juris vinculum de los romanos lo hacen "sin existir en ellos necesidad de ninguna clase y, además, con detrimento de elementales nociones de orden lógico" .

Para este tratadista lo que constituye esencialmente la relación jurídica es la circunstancia de que ciertas normas o reglas de derecho otorgan efectos jurídicos a una relación de la vida de las personas (consigo misma, con personas extrañas, o con cosas). Con respecto a la posesión, "la relación jurídica surge únicamente cuando determinadas normas jurídicas imponen a los demás la obligación o deber de respetar el poder de hecho (o relación material con las cosas) de que son titulares los poseedores" y termina "nadie discute hoy que la posesión es una auténtica relación jurídica en cuanto se encuentra protegida por el ordenamiento jurídico (...)toda posesión se encuentra protegida con la acción directa y las acciones posesorias; lo cual indica que los demás se encuentran obligados a respetar las relaciones materiales que alguien establece con una cosa (...) la relación entre el propietario y la cosa o entre el poseedor y la cosa, es apenas el supuesto de una relación jurídica; ésta se constituye por una serie de normas que protegen al propietario o al poseedor en el goce y el poder de hecho, imponiendo a los demás el deber de respetar la propiedad o posesión" Ahora bien, el autor citado va todavía más allá y nos enseña que la posesión no sólo es una relación jurídica, sino además un derecho real provisional. Es un derecho 
real desde el punto de vista de que la posesión es un poder de hecho que se ejerce sobre cosas y que se encuentra protegida con verdaderas acciones reales (las acciones posesorias), pero es provisional en el sentido de que puede caer frente a la acción que se deriva de la propiedad. Valencia Zea cita a los autores que comparten esta doctrina : A. Von Tuhr (posesión es un derecho real), a Enneccerus y Nypperdey (la posesión jurídicamente protegida es un derecho), Wolff (clasifica los derechos reales en definitivos y provisionales), Leonhard (posesión es un derecho real incompleto), Messineo (posesión es un derecho real de naturaleza interina), G. de Semo (posesión es un derecho real precario), Manresa y Navarro (posesión es un derecho real, pues está protegida con las acciones posesorias), Puig Peña (posesión es un derecho real de naturaleza especial, dada la protección meramente provisional que se le dispensa) .

El autor italiano Francisco Carnelutti es contrario a esta tesis, pues es terminante al señalar que el poseedor no es titular de derecho alguno frente al no poseedor. Recordemos que él sigue el principio romano del jus vinculum restringido al derecho personal entre dos personas. Sin embargo el mismo Carnelutti sostiene que "el poseedor sólo tiene, en primer lugar, derecho (procesal) a que el juez provea en sede jurisdiccional sobre su demanda dirigida a hacer que se declare cierto que él tenía la posesión, y que ha sido perturbado o despojado de ella, derecho que no es más que acción cautelar de cognición. $\mathrm{Y}$ en segundo lugar, una vez que haya obtenido una decisión favorable, derecho a que se provea en sede ejecutiva a restituirle la cosa, si de ella fue despojado, o a eliminar la perturbación (...) En particular el derecho del poseedor despojado a la reintegración es un puro derecho procesal, y más concretamente, acción ejecutiva, esto es, derecho frente al juez, con lo cual se supera la dificultad de reconocer un derecho al poseedor no propietario"

Estamos, pues, ante dos posiciones claramente definidas:

1. La posesión no es una relación jurídica, es un mero hecho, pero atribuye al poseedor la posibilidad de promover una demanda para que se ampare o tutele su situación posesoria.

2. La posesión es una relación jurídica e, incluso, puede llegar a ser un derecho real provisional, y consecuentemente el poseedor tiene expeditas las acciones de tutela que le otorga la ley a este derecho real.

En el Ecuador, y siguiendo las opiniones de los juristas Víctor Manuel Peñaherrera y Juan Larrea Holguín, el Código Civil se inclina por el concepto de que la posesión es un mero hecho, pero sin desconocer que da origen a derechos. Juan Larrea Holguín sostiene que "dentro de nuestro sistema civil positivo, dados sus orígenes históricos (...) la posesión debe apreciarse solamente como un hecho que funda derechos, que da origen a derechos, pero no como un verdadero derecho en sí misma considerada".

No hay que desconocer que para interpretar correctamente una institución, en este caso del Código Civil (como es la posesión) hay que remitirse a las corrientes doctrinarias que la inspiraron. Este conocimiento es el que nos lleva a concluir que en nuestro ordenamiento jurídico la posesión no es un derecho, como lo concibe el pen- samiento moderno, sino un hecho del cual se derivan consecuencias jurídicas importantes. Sin embargo, no es menos cierto que el aporte del derecho comparado nos lleva a nuevas e importantes conclusiones que superan la concepción tradicional, y en el caso específico de la posesión, al elevarla al estado de un derecho real y dotarla de autonomía frente al derecho de propiedad, se abre una nueva perspectiva del estudio de la posesión, quizá mas adecuada al mundo moderno.

\subsection{Acciones posesorias.-}

Hemos visto que la posesión, considerada como un hecho, es objeto de tutela jurídica (derecho procesal). Pero también, considerada como un derecho real provisional, goza de tutela jurídica. En ambos supuestos la protección jurídica se realiza mediante las acciones posesorias.

Según el artículo 980 del Código Civil: "Las acciones posesorias tienen por objeto conservar o recuperar la posesión de bienes raíces o de derechos reales constituídos en ellos". Según este artículo carecen de acción posesoria : a) los poseedores de cosas muebles ; b) los que poseen en virtud del ejercicio de un derecho personal (arrendatarios, depositarios, etc).

Las acciones posesorias protegen la posesión y ella es su único fundamento, a diferencia de las acciones petitorias que se fundamentan en la propiedad. Sin embargo, no debemos olvidar que la tutela jurîdica de la posesión, siguiendo la tendencia romana, a través de los interdictos, no se produce por el hecho de la posesión en sí misma, sino, porque a través de su protección se amparaba indirectamente al derecho de propiedad. En cambio, si adoptamos la actual tendencia, - de considerar a la posesión como un derecho autónomo- las acciones de tutela se encaminan a proteger directamente el derecho de posesión en sí mismo, independientemente del derecho de propiedad. No obstante estas consideraciones, el fundamento actual de las acciones posesorias es la posesión.

La sección décimo primera del Código de Procedimiento Civil, de los Juicios Posesorios, distingue los siguientes juicios posesorios : a) del juicio sobre la posesión efectiva de los bienes hereditarios ; b) de los juicios sobre conservación y recuperación de la posesión ; y c) de los juicios de obra nueva y obra vieja.

Nuestro sistema jurídico parece dividir a las acciones en acciones posesorias comunes y acciones posesorias especiales. Las primeras son las conservación, o para recuperación de la posesión, y las especiales son las de obra nueva y obra vieja que protegen indirectamente la posesión.

Acerca de la naturaleza jurídica del juicio sobre la posesión efectiva de los bienes hereditarios, la doctrina se ha manifestado ampliamente por excluir a este juicio de los de naturaleza posesoria, criterios que han sido recogidos por la Corte Suprema y que son compartidos por quien escribe estas líneas.

Sobre la naturaleza real o personal de estas acciones diremos que esta calificación depende también el que consideremos a la posesión como un hecho generador de efectos jurídicos o como un derecho.

Acciones reales, según el criterio emitido por la Corte Suprema de Justicia citado por Juan Larrea Holguín, son "los medios que la ley concede para hacer declarar en juicio la existencia, plenitud y libertad de los dere- 
chos reales, esto es, de los derechos en la cosa, sin consideración a determinada persona (...)es real la acción que se dirige contra quien impide el derecho de poseer de otros (derecho en la cosa) arrogándose sobre el inmueble ajeno indebida servidumbre" .

Si consideramos a la posesión como un mero hecho, evidentemente, no podría hablarse de acción real. Esta dirección tiene su fundamento en el Derecho Romano que derivó en las acciones posesorias de tipo personal. Sin embargo, el mismo Juan Larrea Holguín, observa que, sin desvirtuar el carácter esencialmente de hecho propio de la posesión en nuestro sistema jurídico, bien puede sostenerse que las acciones posesorias son reales, porque tutelan el derecho a ese hecho, frente a toda clase de personas, o frente a la comunidad en general. En el mismo sentido, Víctor Manuel Peñaherrera opina que las acciones posesorias son reales, como real es el derecho posesorio y esto, porque existe frente a todos .

En definitiva, si adoptamos el criterio moderno de que la posesión es un derecho real, aunque con características propias, no cabe duda sobre la naturaleza real de las acciones posesorias; pero aun si nos mantenemos fieles a la dirección de nuestro Código Civil, que tiende hacia la concepción de la posesión como un hecho pero con consecuencias en el ámbito jurídico, las acciones que tutelan la situación posesoria también son acciones reales.

Ahora bien, las acciones o procesos posesorios, se inician con una pretensión sobre la posesión (su tutela jurídica: conservación y/o recuperación) y terminan mediante una sentencia de declaración de certeza sobre el derecho de posesión, cuya violación debe ser motivo de prueba y sobre los medios necesarios para restablecer la violación de ese derecho. Cuando decimos derecho de posesión, podemos entender que se trata del derecho del poseedor a reclamar del juez la tutela jurídica 0 , desde el punto de vista de las doctrinas más modernas como el derecho real de posesión en sí mismo considerado.

En ambos supuestos estamos ante un proceso cuyo fin es la declaración de certeza de un derecho o de un mero hecho que otorga el derecho a la tutela posesoria; estos dos objetos de declaración o acertamiento coinciden plenamente con el objeto de los procesos de conocimiento, esta coincidencia es la que nos permite ubicar a los procesos posesorios como verdaderos procesos de conocimiento, afirmación con la que concluimos este estudio y cuyo efecto inmediato es el de permitir que este tipo de procesos sean conocidos por la Corte Suprema de Justicia en virtud del recurso de casación.

1. Resolución $N^{\circ}$ 819-98 dictada por la Tercera Sala de lo Civil y Mercantil de la Corte Suprema de Justicia dentro del juicio verbal sumario que por restitución de posesión sigue Dario Ochoa Guamán en contra Aurelio Antonio Ochoa, publicada en el Registro Oficial $N^{\circ} 146$ de 11 de marzo de 1999. Ver también las resoluciones dictadas por esa misma sala, $n^{\circ} 826-98, n^{\circ} 827-98,828-98$ publicadas en el Registro Oficial $N^{\circ} 147$ de 12 de marzo de 1999, $n^{\circ} 15-99$ publicada en el Registro Oficial $N^{\circ} 174$ de 21 de abril de 1999.

2. Jaime Guasp, Derecho Procesal Civil, Tomo 1, tercera edición corregida, editorial Instituto de Estudios Políticos, Madrid, 1968, p. 26 y 27.

3. Francisco Carnelutti, Instituciones del Proceso Civil, Editorial EJEA, Buenos Aires, 1959, p. 23.

4. Enrique Véscovi, Teoría General del Proceso, segunda edición actualiza, editorial Temis, Bogotá, 1999, p. 96 y 97.

5. Memorias de las VIII Jornadas Iberoamericanas de Derecho Procesal, Tomo II, Corte Suprema de Justicia, Quito, 1983.

6. Leo Rosenberg, Tratado de Derecho Procesal Civil, Tomo 1, Ediciones Jurídicas Europa América EJEA, Buenos Aires, 1955, p. 5.

7. Hernando Devis Echandía, Compendio de Derecho Procesal, Tomo 1, Teoría General del Proceso, decimocuarta edición, editorial Abc, Bogotá, 1996, p. 166.

8. Enrique Véscovi, Teoría General del Proceso, Temis, Bogotá, 1984, p. 112.

9. Eduardo Couture, Fundamentos del Derecho Procesal Civil, tercera edición, editorial Depalma, Buenos Aires, reimp., 1993, p. 81.

Jaime Guasp, Derecho Procesal Civil, tercera edición, corregida, Tomo 2, Editorial Instituto de Estudios Políticos, Madrid, 1968, p. 10.

10. Francisco Carnelutti, Sistema de Derecho Procesal Civil, Tomo 1, Introducción y Función del Proceso Civil, Editorial Uteha Argentina, Bueno Aires, 1944, p. 162 y 163

11. Hernando Devis Echandía, op. Citada, p. 164.

12. Carnelutti, Sistema..., p. 173.

13. Carnelutti, Sistema..., p. 173.

14. Guasp, Op. Citada, Tomo 1, p. 546.

15. Carnelutti, Sistema, p. 213.

16. Carnelutti, Sistema, p. 217.

17. Carnelutti, Sistema...,, p. 218)

18. Juan Larrea Holguín, Derecho Civil del Ecuador, reimpresión, de la cuarta 
NOTAS

edición, Tomo V, Los bienes y la Posesión, Corporación de Estudios y Publicaciones, Quito, 1986, p. 98.

19. Carnelutti, Sistema..., p. 247.

20. Tomado del libro de Arturo Valencia Zea, La Posesión, editorial Temis, Bogotá, 1983, p. 183.

21. Rosenberg, Op. citada, tomo 2, p. 15.

22. Arturo Valencia Zea, La Posesión, tercera edición, editorial Temis, Bogotá, 1983, p. 183.

23. Valencia Zea, Op. citada, p. 184.

24. Valencia Zea, op. citada, p. 185

25. Valencia Zea, op. Citada, p. 187 y 188.

26. Francisco Carnelutti, Instituciones del Proceso Civil, volumen 1, editorial EJEA, Buenos Aires, 1959, p. 327.

27. Larrea Holguín, ob. citada., p. 109

28. Resolución $N^{\circ}$ 449-98 dictada por la Primera Sala de lo Civil y Mercantil dentro del juicio sumario $n^{\circ}$ 147-98 de posesión efectiva y diligencia de nombramiento de administrador común de los bienes de la sucesión de Luis Noboa Naranjo, propuesto por Luis Noboa Pontón a Alvaro, Leonor, María Elena, Isabel y Diana Noboa Pontón y publicada en el R. O. $N^{\circ} 40$ de 05 de octubre de 1998.

29. Larrea Holguín, ob. citada, p. 225 y 226

30. Larrea Holguín, ob. citada, p. 225 